\title{
A P19 Cardiac Cell Line as a Model for Evaluating Cardiac Tissue Engineering Biomaterials
}

\author{
Jennifer E. Dawson ${ }^{1,2}$, Sophie Boisvenue, Ilona S. Skerjanc ${ }^{*, 1, \dagger}$ and May Griffith ${ }^{2,3, \dagger}$ \\ ${ }^{I}$ Department of Biochemistry, Microbiology, and Immunology, University of Ottawa. 451 Smyth Road, Ottawa, ON, \\ K1H 8 M5, Canada \\ ${ }^{2}$ Department of Cellular and Molecular Medicine, University of Ottawa. 451 Smyth Road, Ottawa, ON, K1H 8M5, \\ Canada \\ ${ }^{3}$ Ottawa Health Research Institute, Ottawa General Hospital. 501 Smyth Rd. Ottawa ON, K1H 8L6, Canada
}

\begin{abstract}
Our objective was to develop a suitable cardiomyocyte progenitor cell line for use in testing biomaterials as potential scaffolds in cardiac tissue engineering. We transfected P19 cells with the human cardiac $\alpha$-actin promoter driving the gene for puromycin resistance, to create a stable cardiomyocyte-selectable P19 cell line, termed P19(CAPuro). Puromycin selection resulted in a 4-10 fold enrichment of cardiac muscle gene expression and a 3-fold enrichment in cardiomyocytes. Morphological, biochemical, and functional analyses were used to evaluate the properties of P19(CAPuro) cardiomyocytes in the presence and absence of a novel cross-linked collagen-based biomaterial. The collagen-based biomaterial was able to support appropriate viability, gene expression, and cardiomyocyte function. Therefore, P19(CAPuro) cells are suitable for examining biomaterials as potential scaffolds and this approach could be used for rapidly screening biomaterials for designing future human embryonic stem cell therapies.
\end{abstract}

Keywords: Myocardium, biodegradable hydrogel, heart, embryonic stem cells.

\section{INTRODUCTION}

Heart disease such as myocardial infarction is the leading cause of death in developed countries. It is often directly correlated with a loss in functional cardiac muscle and the formation of scar tissue as mature cardiomyocytes have limited abilities to regenerate. Stem cell based cardiomyocyte replacement strategies may offer promise for regenerating the myocardium, demonstrated by recent efforts with human embryonic stem cell (ESC) delivery in the rodent model [1-3]. In addition, the development of tissue engineered cardiac patches, comprised of stem cell derived muscle cells delivered in a biological-based scaffold, is being investigated by numerous groups $[4,5]$. These cardiac muscle patches are designed to integrate into the myocardium and improve contractile function at the site, offering improved cell delivery and integration when compared to injected cells alone. It is generally agreed that the ideal scaffold should mimic the native cardiac extracellular matrix (ECM) microenvironment to allow for incorporated stem or progenitor cells to proliferate and differentiate into cardiaclike muscle in a controlled manner. Many different ECM combinations have been reported in the literature, and some of these scaffolds have shown promising albeit limited success when implanted into mammalian hearts, as reviewed in [6-9]. Common challenges include designing a strong yet

*Address correspondence to this author at the Department of Biochemistry, Microbiology, and Immunology, University of Ottawa. 451 Smyth Road, Ottawa, ON, K1H 8M5, Canada; Tel: (613) 562-5800 x 8669; Fax: (613) 562-5440; E-mail: iskerjan@uottawa.ca

$\dagger$ Designates equal contributions by both authors biodegradable scaffold, controlling cardiomyocyte differentiation, and functional host-graft integration of the patch $[5$, $7,10,11]$. A limiting factor to solving these tissue engineering problems is the lack of a homogeneous, readily available source of cardiomyocyte stem cells for use in testing new materials as potential scaffolds. In this study, we report the derivation of a model cardiomyocyte progenitor line for use in evaluating different biomaterials as potential scaffolds for cardiac tissue engineering.

P19 embryonic carcinoma (EC) cells have been widely used to model cellular differentiation during embryonic development. Originally derived from an induced murine embryonic teratocarcinoma [12], P19 EC cells are pluripotent and can differentiate into all three germ layers after cellular aggregation (a process similar to embryoid body formation) [13]. In response to cardiomyogenic inducers in culture, rhythmically contracting areas begin to appear by 8 14 days in $8-25 \%$ of the P19 EC embryoid bodies [14], and these express cardiomyogenic-related transcription factors and proteins [15-17]. P19 cell differentiation requires similar signalling pathways and transcription factors as those observed during early embryonic development and in mouse ES cell differentiation [18]. Further, P19 cells can contribute to murine heart formation in chimeric mice in vivo [19]. Functional ion channels have been demonstrated in P19 derived cardiomyocytes [20], and were found to be similar to in vivo derived neonatal, embryonic and ESC cardiomyocyte cultures [20-23]. Therefore, P19 EC cells can be readily used to model ESC differentiation into cardiac muscle, forming functional, beating cardiomyocytes [24-27]. 
While human embryonic stem cells are ideal for future cell therapies to regenerate the myocardium, the growth and differentiation of these cells is much more difficult, labour intensive, and time consuming than P19 cell cardiomyogenesis $[18,28]$. Thus P19 cells could be used as a rapid screen to optimize methods to use for future human ES cell cardiac muscle therapies. Despite these attractive properties, the actual utility of P19 EC and human ES cells in studying cardiac muscle formation has been limited due to the relatively low efficiency of cardiac muscle induction. In order to optimize utility for P19 cells, we have developed stable P19 cell lines with the ability to select for cardiomyocytes. Cardiac $\alpha$-actin, often used as a marker of muscle differentiation, is expressed throughout cardiac muscle development and also in embryonic skeletal muscle [29]. In the present study, we developed a cardiac $\alpha$-actin selectable cell line, in which the cardiac $\alpha$-actin promoter drives puromycin resistance, termed P19(CA-Puro), to obtain cultures enriched in cardiomyocytes. We report that our P19(CA-puro) line efficiently differentiates into functional cardiac muscle, and provides a useful tool in characterization of biomaterials for cardiac tissue engineering.

\section{MATERIALS AND METHODS}

\section{P19 Cell Culture}

P19 cells (American Type Culture Collection \#CRL1825 , Virginia, USA) were cultured in $\alpha$-minimum essential media ( $\alpha$ MEM) (Invitrogen, Ontario, Canada) supplemented with $10 \%$ fetal bovine serum (FBS) (CanSera, Rexdale, Canada) and $50 \mu \mathrm{g} / \mathrm{ml}$ of gentamycin (Invitrogen). They were plated at $1 \times 10^{5}$ cells $/ \mathrm{ml}$ media and passaged every two days.

\section{Plasmid Constructs}

In order to create our cardiac $\alpha$-actin selectable cell line, we designed an expression construct, termed Human cardiac actin-puromycin (HCA-puro) in which the puromycin resistance gene is under control of an HCA promoter. The expression construct HCA-puro was cloned into the BSK+ expression vector, and contains a Sal/HindIII 450 base pair HCA promoter (25), driving a HindIII/Bs1 II $1 \mathrm{~Kb}$ puromycin resistance fragment from PGK-puro. The empty PGK vector was used as a control. The constructs PGK-Neo, B17, and PGK LacZ were previously described [30].

\section{Stable Cell Line Generation}

For transfections $2.04 \mu \mathrm{g}$ of CA-Puro, $0.09 \mu \mathrm{g}$ of PGKNeo, $0.17 \mu \mathrm{g}$ of PGK-LacZ, and $0.77 \mu \mathrm{g}$ of B17, were mixed, added to the FuGENE ${ }^{\mathrm{TM}} 6$ reagent (Roche Applied Science, Quebec, Canada), and incubated with $2.5 \times 10^{5}$ cells in 35-mm tissue culture dishes. Controls comprised of P19 cells transfected with CA-LacZ, PGK-Neo, PGK-LacZ, and $\mathrm{B} 17$. The $\mathrm{B} 17$ construct is a $17 \mathrm{~Kb}$ portion of the $p g k-1$ gene and has been shown to enhance the formation of stable cell lines in P19 cells, by an unknown mechanism [31]. $\beta$ galactosidase assays were used to determine the transfection efficiency for each experiment as described [32]. Cells were selected for G418 resistance $(500 \mu \mathrm{g} / \mathrm{ml})$ (Sigma Aldrich, Ontario, Canada) for 7 days. The high ratio of CA-Puro to PGK-neo plasmids increases the chance of G418-resistant clones containing the CA-puro plasmid. 48 stable P19(CApuro) clonal populations were isolated and examined for their low expression of puromycin transcripts (RNA) and their high content of HCA-puro DNA by slot-blot analysis as previously described [33]. Stable cells lines that met this criteria were termed P19(CA-puro), and further tested for their ability to differentiate into puromycin resistant cardiomyocytes.

\section{P19(Control) and P19 (CA-puro) Differentiation into Cardiomyocytes}

P19(CA-puro) and control cells were allowed to reach confluence, passaged, and then placed under differentiation conditions. Cells were aggregated in the presence of $0.8 \%$ Dimethyl Sulfoxide (DMSO) (Sigma Aldrich) in 10\% FBS (PAA, Austria), aMEM (Invitrogen) for 4 days and then plated onto tissue culture dishes [12]. On days $0,4,6,8$ of differentiation, selection was initiated by treating cells with $2 \mu \mathrm{g} / \mathrm{ml}$ puromycin in the growth medium. Cultures were maintained until day 12 . On day 12 , cultures were assessed for cell viability (by trypan blue exclusion), and fixed for immunocytochemistry with myosin heavy chain (MHC) antibody. P19(Control) cells served as selection controls. For cardiomyocyte selection experiments, cells were treated with $2 \mu \mathrm{g} / \mathrm{ml}$ puromycin (or $0 \mu \mathrm{g} / \mathrm{ml}$ for controls) starting on day 6 of differentiation. $\alpha \mathrm{MEM}$ was changed daily.

\section{Quantitative Polymerase Chain Reaction (QPCR)}

To determine the extent of enrichment of cardiomyocytes with puromycin selection, changes in gene expression of cardiac muscle genes, (Table 1), were examined by QPCR. Briefly, RNA was isolated using Trizol (Invitrogen) on Day 9 of differentiation from P19(CA-puro) cells with and without puromycin treatment starting on Day 6. QPCR was performed, and the fold increase in expression changes associated with the puromycin selection was calculated relative to the P19(CA-puro) Day 9 non-puro treated control RNA. cDNA synthesis was performed using the SuperScript ${ }^{\mathrm{TM}}$ III Reverse Transcriptase kit as suggested by the manufacturer (Invitrogen). QPCR was performed using SYBR Green PCR Master Mix (Applied Biosystems, California, USA), following manufacturer's suggestions in a $25 \mathrm{ul}$ final reaction volume. PCR amplification was performed using a BioRad iCycler thermocycler with the following conditions: an initial denaturing at $95^{\circ} \mathrm{C}$ for 10 minutes, 40 cycles of $95^{\circ} \mathrm{C}(15$ seconds $) / 60^{\circ} \mathrm{C}$ (30 seconds) $/ 72^{\circ} \mathrm{C}(30$ seconds), and a final extension at $72^{\circ} \mathrm{C}$ for 10 minutes. A melt curve analysis was performed as follows: $95^{\circ} \mathrm{C}$ for 1 minute, $55^{\circ} \mathrm{C}$ for 1 minute, and $55^{\circ} \mathrm{C}$ for 10 seconds with an increase of $0.5^{\circ} \mathrm{C}$ at each successive cycle for 80 cycles. The oligonucleotide primers for $\alpha$-actin, Atrial Natriuretic Peptide (ANP), MHC, GATA4, Pax-3, MyoD, and GAPDH are given in Table $\mathbf{1}$. These primers have been previously validated for their efficiency of amplification under these conditions, including a melt curve analysis and by comparison with results from Northern Blot analysis. Relative fold differences in expression of these genes between the P19(CA-puro) (+) puro and P19(CA-puro) (-) puro control cells were calculated using the comparative $C_{T}$ method [34]. Briefly, the difference in cycle time $\Delta \mathrm{C}_{\mathrm{T}}$, was calculated by normalizing the values relative to the reference gene, 
Table 1. Primers and their Respective References used in QPCR Reactions

\begin{tabular}{|c|c|c|c|}
\hline Gene of Interest & Forward Primer & Reverse Primer & Reference \\
\hline \hline Myosin Heavy Chain (MHC) & ACAACCCCTACGATTATGCGT & ACGTTCAAAGGCACTATCCGTG & {$[61]$} \\
\hline Gata-4 & AAACGGAAGCCCAAGAACCT & TGCTAGTGGCATTGCTGGAGT & {$[62]$} \\
\hline Atrial Natriuretic Peptide (ANP) & ACTAGGCTGCAACAGCTTCC & TGACACACCACAAGGGCTTA & {$[63]$} \\
\hline Cardiac $\alpha$-actin & CTGGTATTGCCGATCGTATG & CTTGCTGATCCACATTTGCT & {$[61]$} \\
\hline MyoD & CCCCGGCGGCAGAATGGCTACG & GGTCTGGGTTCCCTGTTCTGTGT & {$[64]$} \\
\hline Pax3 & TTTCACCTCAGGTAATGGGACT & GAACGTCCAAGGCTTACTTTGT & {$[61]$} \\
\hline GAPDH (Glyceraldehyde 3-phosphate dehydrogenase) & AGGTCGGTGTGAACGGATTTG & TGTAGACCATGTAGTTGAGGTCA & {$[61]$} \\
\hline
\end{tabular}

GAPDH. $\Delta \Delta \mathrm{C}_{\mathrm{T}}$ was obtained by finding the difference between P19(CA-puro) (+) puro (target) and the control (-) puro cells (baseline). The equation $\Delta \Delta \mathrm{C}_{\mathrm{T}}=\Delta \mathrm{C}_{\mathrm{T}}$ (target) $\Delta \mathrm{C}_{\mathrm{T}}$ (baseline) was used. The effect of the collagen substrate on gene expression in P19(CA-puro) was investigated by determining the fold change in gene expression of P19(CApuro) $(+)$ puro cells growing on the substrate, and using P19(CA-puro) (+) puro cells growing on tissue culture plates as the baseline. The relative fold change in gene expression level was determined by calculating $2^{-\Delta \Delta \mathrm{CT}}[35]$.

\section{Immunocytochemistry}

Differentiated aggregates grown on gelatin coated coverslips were fixed on day 9 or 12 in $-20{ }^{\circ} \mathrm{C}$ methanol (for MHC), and with Lana's Fixative (1.6\% paraformaldehyde in $9 \%$ Picric Acid) for cardiac $\alpha$-actin, actinin, troponin-T, and GATA4. For MHC immunocytochemistry, cells were rehydrated in stockholm's phosphate buffered saline (sPBS) (1M $\mathrm{Na}_{2} \mathrm{HPO}_{4}, 5 \mathrm{M} \mathrm{NaH} \mathrm{PO}_{4}, 70 \mathrm{mM} \mathrm{NaCl}, 4 \mathrm{M} \mathrm{KCl}$ ), and $\mathrm{MHC}$ expression was detected utilizing the monoclonal MF20 antibody supernatant (Developmental Studies Hybridoma Bank, Iowa City, IA USA) as described previously [33]. For cardiac $\alpha$-actin, actinin, troponin-T, and GATA4 immunocytochemistry, fixed coverslips were blocked with $4 \%$ Goat Serum, $0.3 \%$ Triton-X, and incubated with the respective antibodies, as summarized in Table 2 . In all staining, nuclei were detected with 1:10000 DAPI and washed well with sPBS. Coverslips were mounted on glass slides and visualized with a Zeiss Axioskop microscope. Isotype matched controls were used for all antibodies and background fluorescence was taken into account at all magnifications analyzed. Cardiomyocyte and total cell counts were performed to quantify the percentages of MHC positive cardiomyocytes in our cultures. This was performed by counting five images from two coverslips for each data point in two independent experiments.

\section{Collagen Hydrogels}

Rat tail collagen I $(4.75 \mathrm{mg} / \mathrm{ml})$ (BD Biosciences, Ontario, Canada) was mixed with collagen buffer (1M HEPES, 10x Dulbecco's-MEM (FBS-free), and 7.5\% sodium bicarbonate) at a ratio of $7: 1 \mathrm{v} / \mathrm{v}$ on ice. The $\mathrm{pH}$ of the collagen mixture was then adjusted to 7.4 with $1 \mathrm{~N} \mathrm{NaOH}$, and $5 \mathrm{mM}$ calcium chloride and $1 \mathrm{mM}$ DL-dithiothreitol (DTT) were added. Cross-linking was performed with $0.22 \mathrm{U} / \mathrm{ml}$ guinea pig transglutaminase (Sigma Aldrich), and the viscous solution was dispensed into the desired moulds as follows: $200 \mu \mathrm{l}$ for $12 \mathrm{~mm}$ transwell tissue inserts (Corning, Massachusetts, USA), and $250 \mu 1$ for the EcoMEA dishes (Microelectode Array Systems, Germany), and then thermogelled at $37^{\circ} \mathrm{C}$ for 45 minutes. $10 \%$ FBS $\alpha \mathrm{MEM}$ media and P19(CA-puro) aggregates were added on top of

Table 2. Antibodies used for Immunocytochemistry Experiments

\begin{tabular}{|c|c|c|}
\hline Antibody & Antibody Dilution & Company \\
\hline Myosin Heavy Chain (MF20) & $1: 2$ in $\mathrm{sPBS}$ & Developmental Studies Hybridoma Bank, Iowa, USA \\
\hline Cardiac $\alpha$-actin & $1: 500$ in $4 \%$ goat serum, $0.3 \%$ triton $X-100$ & Fitzgerald, MA, USA \\
\hline TroponinT & $1: 500$ in $4 \%$ goat serum, $0.3 \%$ triton $\mathrm{X}-100$ & LabVision,QC,Canada \\
\hline Gata4 & $1: 100$ in $4 \%$ goat serum, $0.3 \%$ triton $X-100$ & Santa Cruz Biotech Inc. CA, USA \\
\hline Sarcomeric Actinin & $1: 1000$ in $4 \%$ goat serum, $0.3 \%$ triton $\mathrm{X}-100$ & Sigma-Aldrich \\
\hline Goat Anti-mouse Cy3 & $1: 400$ in block for secondary staining & The Jackson Laboratory, Maine, USA \\
\hline Goat Anti-mouse FITC & $1: 1000$ in block & The Jackson Laboratory, Maine, USA \\
\hline Anti-Goat FITC & $1: 500$ in block & The Jackson Laboratory, Maine, USA \\
\hline Goat IgG & $1: 100(30 \mu \mathrm{g} / \mathrm{ml})$ in $4 \%$ goat serum, $0.3 \%$ triton $\mathrm{X}-100$ & Invitrogen, Ontario, Canada \\
\hline Mouse IgG1 & $2 \mu \mathrm{g} / \mathrm{ml}$ (in $4 \%$ goat serum, $0.3 \%$ triton $\mathrm{X}-100$ ) & Invitrogen, Ontario, Canada \\
\hline Mouse IgG2b & $2 \mu \mathrm{g} / \mathrm{ml}$ in SPBS & Zymed Labortories, California, USA \\
\hline
\end{tabular}


the gels. Media was replaced every day, and the cells were treated with $2 \mu \mathrm{g} / \mathrm{ml}$ puromycin for enrichment on Day 6,7 , 8 , and 9 of differentiation as described above.

\section{Viability Assay}

Cells were grown on top of the collagen gels and control tissue culture dishes (as described above) for one to seven days, and analyzed with the Live/Dead Viability and Cytotoxicity Kit (Invitrogen) according to the manufacturer's instructions. Briefly, gels containing cells were incubated with Calcein AM (esterase activity of viable cells visualized as green fluorescence) and Ethidium homodimer1 (fluorescent red nuclear stain specific for non-viable cells). Hoechst 33342 staining was used for total cell nuclear detection. The gels were then washed well with PBS and immediately visualized with a Zeiss inverted florescent microscope. Three representative images were acquired for each sample for analysis. ( $\mathrm{n}=3$ independent samples).

\section{Microelectrode Array Analysis}

Collagen hydrogel mix was dispensed as $250 \mu 1$ aliquots into $22 \mathrm{~mm}$ microelectrode array (MEA) dishes (Multichannel Systems), and P19(CA-puro) cells were differentiated on top as described above. The MEA dishes contained 60 electrodes recording extracellular potentials. Between Day 9 and 12 of differentiation, the MEA grown cardiac hydrogels were washed with Tyrodes buffer containing $\mathrm{Ca}^{2+}$ (pH 7.4) for 5 minutes and the baseline extracellular potential was examined, as described previously [36, 37]. All readings were taken at $37^{\circ} \mathrm{C}$. A final concentration of $100 \mu \mathrm{M}$ isoproterenol (Sigma Aldrich) diluted in warmed tyrodes buffer was then added to the cardiac gel, and readings were taken from 1-5 minutes after the drug was added. After a drug response was observed, the gel was washed with buffer for 5 minutes, and a "drug recovery" extracellular potential recording was taken.

\section{Statistical Significance}

Values are reported as mean +/- SD (standard deviation). For QPCR, each gene and sample group was tested in duplicate reactions in three biologically independent experiments. Statistical significance was evaluated using unpaired student's t-tests to compare between two treatment groups. Significance level was set at a $\mathrm{p}<0.05$.

\section{RESULTS}

\section{Enrichment for Cardiac Muscle and Characterization of the Cardiomyocytes}

Stable P19 cells were isolated after transfection with the gene for puromycin resistance driven by the cardiac $\alpha$-actin promoter, termed P19(CA-puro). P19(CA-puro) cells
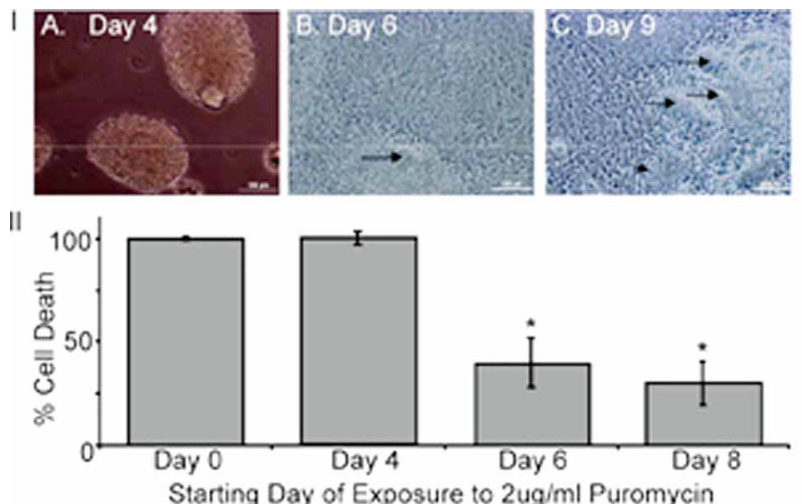

III
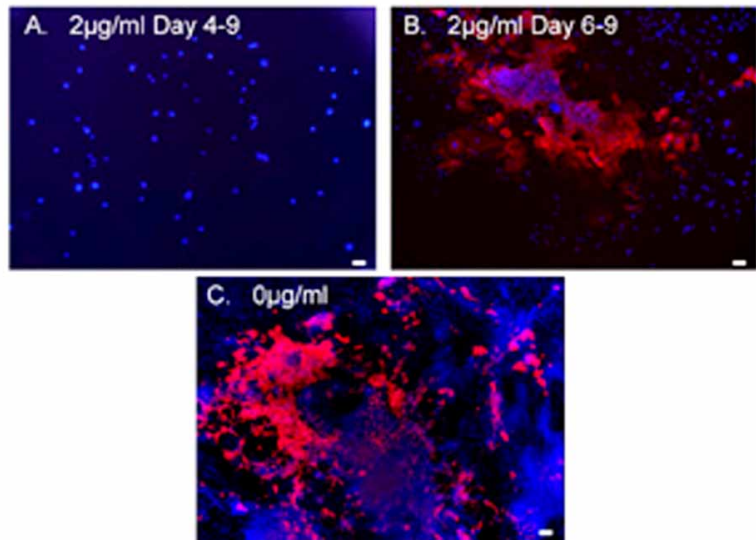

Fig. (1). Cardiomyocyte enrichment from P19(CA-puro) cultures during differentiation. Panel I: P19(CA-puro) cultures differentiated into beating cardiomyocytes by day 6 with DMSO exposure . Arrows depict visibly beating colonies. Panel II: Differentiating P19(CA-puro) cells were exposed to $2 \mu \mathrm{g} / \mathrm{ml}$ of puromycin at different timepoints from day 4-9 of differentiation, and percentage of cell death was calculated on Day 12 of differentiation. Data represents the average $+/$ - SD of three experiments, $*=p<0.05$. Panel III: Muscle formation was visualized by immunocytochemistry with the MF20 antibody against MHC on day 12 (Panel III). Cells were treated with puromycin on days 4-9 (Panel A), days 6-9 (Panel B), or without puromycin (Panel C). For all images (scale bar $=100 \mu \mathrm{m})$. 


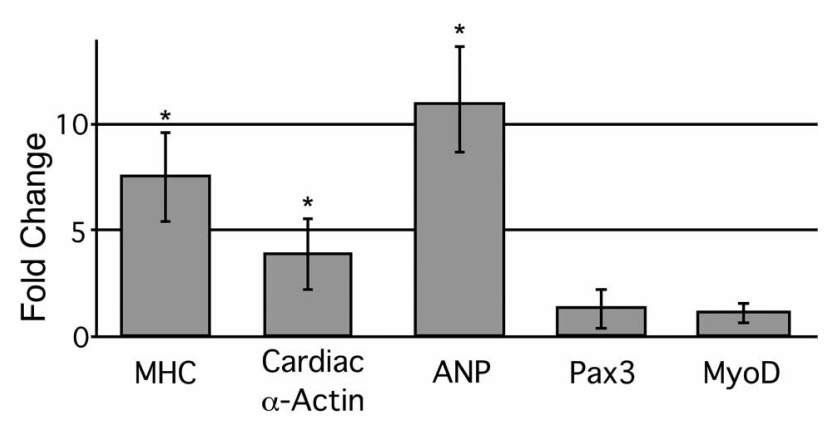

Fig. (2). Cardiac muscle gene expression is enriched by puromycin selection of P19(CA-puro). Differentiated P19(CA-puro) cells were exposed to $0 \mu \mathrm{g} / \mathrm{ml}$ or $2 \mu \mathrm{g} / \mathrm{ml}$ puromycin from day 6-9 of differentiation. RNA was harvested and analyzed with QPCR for primers specific for cardiomyocytes, skeletal muscle, and neural crest cells. Data represents the average $+/-$ SD of 3 independent experiments done in duplicate, $*=p<0.05$.

responded to DMSO induction by differentiating into beating cardiomyocytes after 6 days of differentiation (Fig. 1, panel I). P19(CA-puro) and P19(Control) cells were differentiated and treated with puromycin starting on day 4,6 , or 8 , until day 9. An example of the beating can be seen in supplementary file 1. Puromycin treatment starting on days 6 or 8 resulted in $65 \%$ viability of $\mathrm{P} 19(\mathrm{CA}$-puro) cells (Fig. 1, panel II). Puromycin treatment of P19(Control) cells or P19(CA-puro) cultures on days $0-4$, showed $100 \%$ cell death, reflecting the lack of cardiac $\alpha$-actin expression. Immunocytochemistry of P19(CA-puro) cells treated with puromycin from Day 6-9 showed a greater loss of total cells, compared to $\mathrm{MHC}$ positive cells, resulting in a relative enrichment in MHC positive cells, compared with cells not exposed to puromycin (Fig. 1, Panel III). The slight decrease in cardiomyocyte number could be due to selective silencing of the transgene in some cardiomyocytes or the loss of puromycin-resistant cardiomyocytes due to their attachment to the plate via puromycin-sensitive cells. Thus, selection with puromycin from days 6-9 of P19(CA-puro) differentiation appeared to be optimal during DMSO differentiation, reflecting the expected pattern of cardiac $\alpha$-actin expression [38].

To evaluate the extent of cardiomyocyte enrichment in P19(CA-puro) with puromycin treatment, changes in the expression of cardiomyocyte-specific transcripts were assessed using QPCR. Puromycin selection on Day 6-9 of differentiation in P19(CA-puro) induced a 4-10 fold increase in gene expression of the cardiac muscle related transcripts MHC, ANP, and $\alpha$ actin (Fig. 2). No significant increase in gene expression was measured for MyoD, which is indicative of skeletal muscle development, or Pax3, which marks both skeletal and neural crest precursors.

To confirm the gene expression results with protein expression analysis, and determine the extent of cardiomyocyte enrichment, immunocytochemistry was performed on fixed P19(CA-puro) cardiomyocytes. MHC expression was eva-
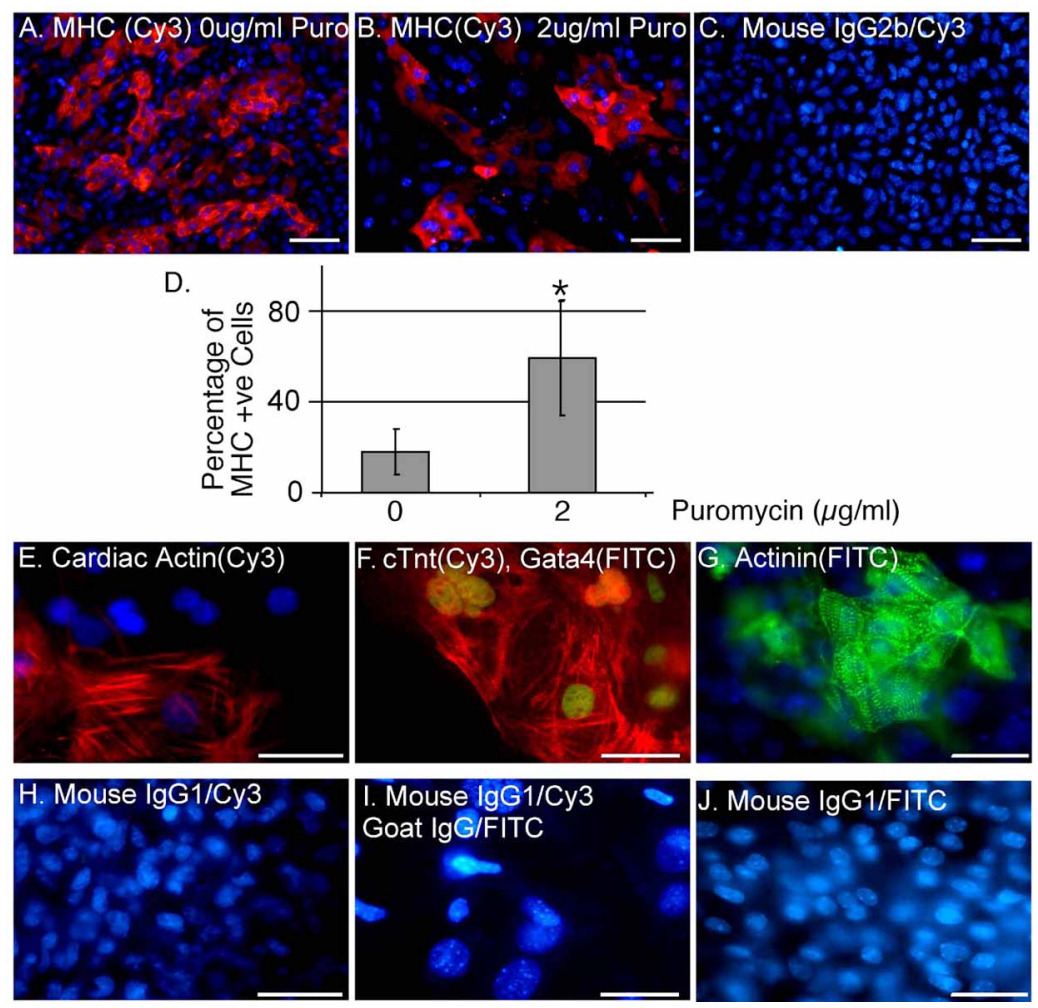

Fig. (3). Cardiomyocytes are enriched in cultures treated with puromycin. Immunocytochemistry was performed for MHC expression in P19(CA-puro) cultures treated with and without puromycin (Panel A, B) and the mouse IgG2b isotype control is shown in panel C. The percentage of MHC positive cells was quantified by cell counting $*=p<0.05$ (Panel D). Cardiomyocytes within the P19(CA-puro) enriched cultures expressed Cardiac $\alpha$-Actin (E), Troponin T and GATA4 (F), and Sarcomeric Actinin (G). Control coverslips were stained with their respective isotype matched controls and are shown in H-J. Mouse IgG1 (for cardiac $\alpha$-actin, Troponin T, Actinin), Goat IgG (for GATA4). All coverslips are stained with DAPI for nuclear detection (blue). Scale bars $=100 \mu 1$. 
luated in P19(CA-puro) cultures with or without puromycin treatment, again showing a greater loss of total cells than cardiomyocytes (Fig. 3A,B). Quantitative analysis indicated that in the absence of puromycin selection $18+/-9 \%$ of the total cells were MHC positive. In contrast, $59+/-19 \%$ of the total cells were MHC positive after puromycin selection from Days 6-9 (Fig. 3B and C). P19(CA-puro) derived cardiomyocytes also expressed cardiac $\alpha$-actin (Fig. 3D), troponin T and GATA4 (Fig. 3E), and $\alpha$ actinin (Fig. 3F) proteins.

Therefore, selection of puromycin resulted in a 3-fold enrichment in the number of cardiomyocytes in P19(CApuro) cell cultures. This cardiomyocyte enrichment was obtained by the selective loss of the non-cardiac muscle cells resulting from the puromycin exposure.

\section{Evaluation of P19(CA-puro) Cardiomyocytes on a Collagen Hydrogel}

To test the compatibility of the transglutaminase crosslinked type I collagen hydrogel as a substrate for cardiomyocytes, the viability of P19(CA-puro) cells was first evaluated.
P19(CA-puro) cardiomyocyte viability on collagen hydrogels and on untreated tissue culture dishes was evaluated, and no significant differences in cell death was measured at both the 24 hour or 7 day time point (Fig. 4).

To test whether growth on the hydrogel affected the cardiomyocyte phenotype, changes in gene expression was evaluated using QPCR. P19(CA-puro) cardiomyocytes maintained their up-regulation of cardiomyocyte marker transcripts under the selective conditions while growing in the collagen hydrogel (Fig. 5). This suggests that the collagen substrate is conducive to maintaining the cardiomyocytes.

To examine the functionality of P19(CA-puro) derived cardiomyocytes, a MEA analysis was performed in the presence and absence of isoproterenol (Fig. 6). P19(CApuro) cardiac muscle cells on collagen gels emitted evenly spaced extracellular electrical events. The number of electrical events per minute were counted and a comparison was made between baseline and isoproterenol treatment groups which was expressed as fold change over baseline. They exhibited an average of 3-fold chronotropic increase between control baseline readings and $100 \mathrm{uM}$ isoproterenol

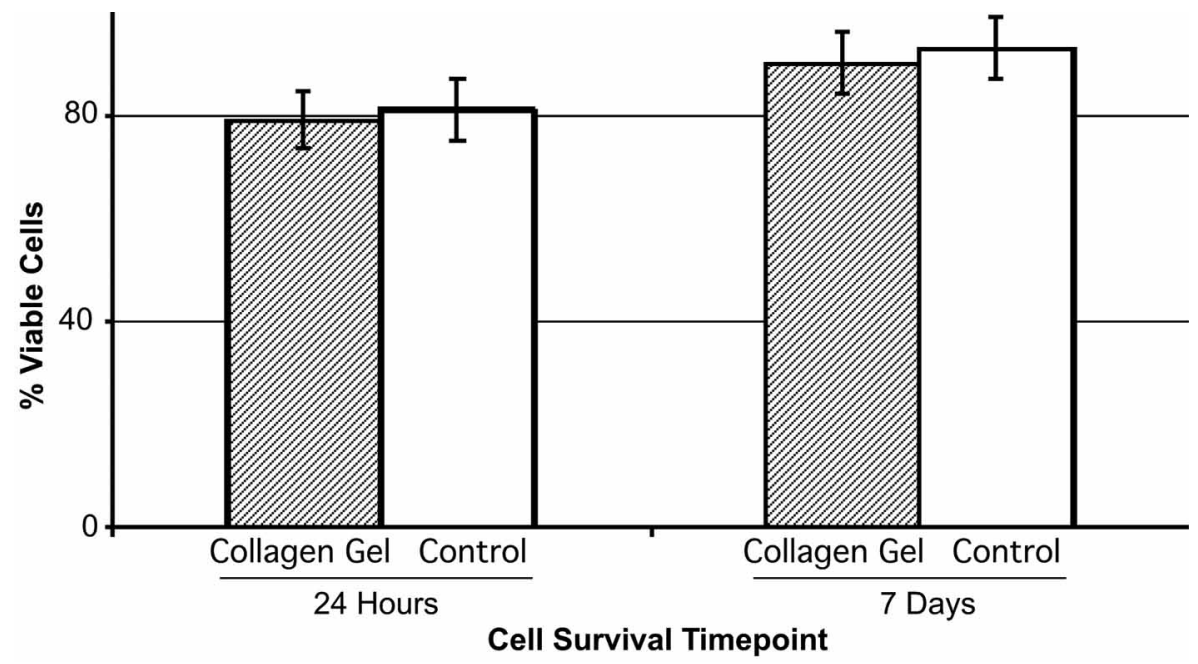

Fig. (4). P19(CA-puro) are viable on a collagen I gel. The cellular viability of P19(CA-puro) was assessed at the 24 hour and 7-day timepoints of growth and was used as a preliminary indicator of the suitability of this particular scaffold for the delivery of cardiac cells. No significant differences were observed between the collagen gel and the control surfaces $(\mathrm{p}>0.05)$.

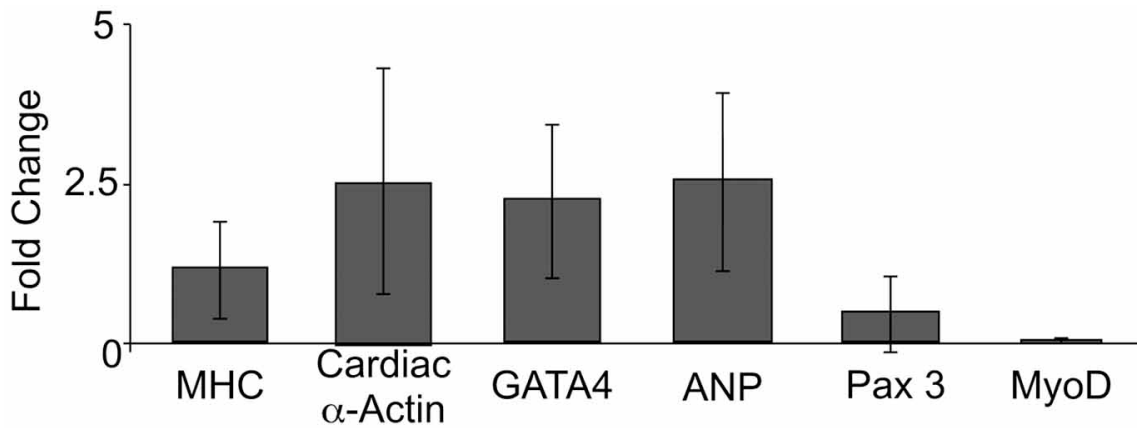

Fig. (5). P19(CA-puro) cardiomyocytes maintain expression of cardiac muscle genes while growing on the collagen gel compared to controls. QPCR analysis of P19(CA-puro) enriched cells growing on the collagen gel and on control tissue culture dishes was performed on Day 9 of differentiation. There was no loss in expression detected in the cardiac transcripts MHC, cardiac $\alpha$-actin, GATA4, or ANP compared to controls. In addition, no gain in skeletal muscle related transcripts was detected (Pax 3 or MyoD). Data represents the average $+/$ SD of 3 independent experiments done in duplicate, $\mathrm{p}>0.05$. 
A. Baseline Reading

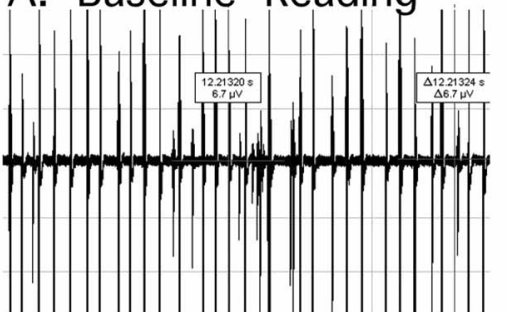

C. Post Drug Washout
B. $100 \mu \mathrm{M}$ Isoproterenol

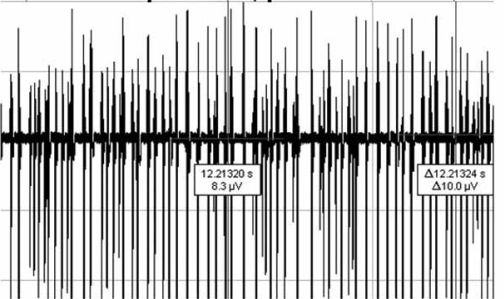

D. Non-Differentiated

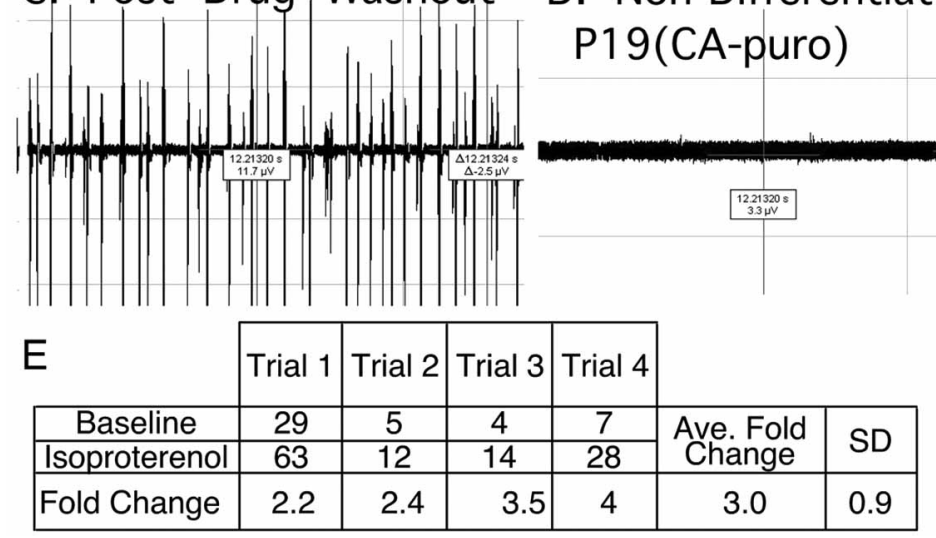

Fig. (6). P19(CA-puro) responds to the adrenotropic agonist isoproterenol. P19(CA-puro) shows a chronotropic response to isoproterenol while growing on our collagen I crosslinked matrix. A-D are an example of an electrode reading from one trial, the complete data (Fold change of \# events recorded per minute) is shown in $\mathrm{E}$.

readings $(\mathrm{p}<0.05)$, with subsequent recovery back to baseline after 5 minutes of drug removal. Undifferentiated P19(CApuro) cells did not exhibit any detectible electrical events, nor did they respond to the drug stimulation. Therefore, collagen substrates are compatible with cardiomyocyte differentiation, as determined by the maintenance of synchronous extracellular electrical events, and the appropriate response to isoproterenol.

\section{DISCUSSION}

Cell based therapies to repair and regenerate cardiomyocytes have shown modest success but are promising. There is evidence that such therapies can be enhanced by incorporation of biomaterial scaffolds to prevent death of implanted cells, as well as to provide appropriate bioactive factors for cell survival and differentiation. A current limitation in cardiac biomaterials research is the availability of large homogeneous populations of cardiac muscle progenitor cells. For the present study we show the creation of a stable cell line that can be enriched for cardiac muscle cells with puromycin selection. Characterization of these derived cardiomyocytes indicated that these cells exhibited many properties of embryonic cardiomyocytes. In addition, we found that the cardiac muscle phenotype of the P19-derived cardiomyocytes was maintained when growing on collagen, a commonly used natural material in tissue engineering

A similar cardiac muscle cell enrichment strategy has been employed using human and mouse ESCs, in which a MHC promoter drove antibiotic resistance or GFP expression [39-47]. A previous publication reported an 99\% purity for human ESC-derived cardiomyocytes used the $\alpha$-MHC promoter driving neomycin resistance approach [44]. The higher enrichment in these ES studies may be due to differences in the promoter specificity due to an integration site in the cells such as near strong lineage-dependent enhancers, the nature of the construct, or simply differences in the method of assessing enrichment.

Our genetically modified P19 cell line, P19(CA-puro), can be selected for cardiac $\alpha$-actin expressing cells with puromycin during differentiation, resulting in about $59 \%$ of cells consistently differentiating into cardiomyocytes compared to $18 \%$ control P19 differentiations. This shows that transfection of P19 cells with the cardiac $\alpha$-actin promoter driving puromycin resistance is an effective methodology for creating a cardiomyocyte selectable model progenitor line.

In response to DMSO induction, P19 cells will differentiate into cardiac and skeletal myogenic lineages. Cardiac $\alpha$ actin expression begins on approximately Day 6 after DMSO induced differentiation of cardiomyocytes, and on approximately day 8-9 in differentiating skeletal muscle [17]. The promoter for human cardiac $\alpha$-actin was first tested in P19 cells in 1988, and it was shown that the transfected promoter functions in the appropriate developmental manner during differentiation of P19 EC cells to cardiomyocytes [17, 38, $48,49]$. In our experiments, this $\alpha$ actin promoter was used to enrich for cardiomyocytes in P19(CA-puro) as differentiating cells were exposed to puromycin on Day 6-9 and cells expressing $\alpha$ actin survived the puromycin selection. RNA and protein analysis, morphological analysis, contractile ability, and the appropriate response of P19(CA-puro) cardiac muscle to the cardioactive drug isoproterenol, demonstrate that P19(CA-puro) cells differentiate into functional cardiac muscle cells. In addition, by selecting for $\alpha$ actin expressing 
cells prior to skeletal expression, we did not observe enrichment for skeletal muscle, as confirmed by the lack of change in expression of the myogenic transcription factors MyoD and Pax3.

Collagen I is the major constituent of the cardiac extracellular matrix, and has been used quite extensively in previous reports as a base for tissue engineered patches, as reviewed in [50, 51]. In this study, we examined the effect of collagen substrate for P19 cardiomyocyte differentiation. We selected a natural crosslinking system for collagen hydrogel preparation to facilitate a natural biodegradable substrate. Transglutaminase is a calcium dependent enzyme that mediates covalent bond formation between glutamine and lysine residues, providing amide bonds which reinforce the scaffold [52, 53], and it has been previously shown that transglutaminase increases the strength of different types of hydrogels, including collagen [54-58]. To date a transglutaminase cross-linked collagen gel has not been published as a substrate for cardiac muscle cells. P19(CA-puro) cells grown on the collagen hydrogel substrate maintained similar levels of cardiomyocyte differentiation, as determined by GATA4, MHC, ANP, and cardiac $\alpha$-actin and transcript levels, compared to the control substrate (untreated tissue culture dishes). Microelectrode arrays allow for the measurement of extracellular field potentials of cultured cells, similar to electrocardiograms [59]. Analysis of the beating-nature of the cardiomyocytes growing on collagen substrates using microelectrode array analysis to detect electrical events showed cardiomyocyte chronotropic stimulation. The P19 (CA-puro) derived cardiomyocytes displayed regular pulsing events that were similar to that described for human ESC derived cardiomyocytes [39, 59, 60], and neonatal isolated cardiac muscle cells [37]. The ability of our substrate to sustain and support functional cardiomyocytes will allow for cardiac muscle cell sheets to be grown in culture for transplantation in the future.

\section{CONCLUSION}

In summary, we created a stable selectable P19 embryonic carcinoma cell line, P19(CA-puro), that can be induced to differentiate into functional cardiac muscle cells. This P19-EC cell based model appears to be a reliable source for evaluating biomaterials, which can next be validated using human ESCs or other muscle cells for therapeutic use such as in tissue engineered scaffolds and/or cell delivery systems for cardiac muscle repair.

$$
\begin{aligned}
& \text { ABBREVIATIONS } \\
& \alpha \text { mem }=\text { Alpha minimal essential media } \\
& \mathrm{ANP}=\text { Atrial natriuretic peptide } \\
& \text { DMSO = Dimethyl sulfoxide } \\
& \text { DTT }=\text { DL-dithiothreitol } \\
& \mathrm{EC}=\text { Embryonic carcinoma } \\
& \mathrm{ESC}=\text { Embryonic stem cell } \\
& \mathrm{ECM}=\text { Extracellular matrix } \\
& \text { FBS }=\text { Fetal bovine serum }
\end{aligned}
$$
$\mathrm{HCA}=$ Human cardiac $\alpha$-actin
MEA = Microelectrode array
MHC = Myosin heavy chain
$\mathrm{QPCR}=$ Quantitative real time polymerase chain reaction
$\mathrm{SD}=$ Standard deviation
sPBS = Stockholm's phosphate buffered saline

\section{ACKNOWLEDGEMENTS}

Funded in part by a Canadian Stem Cell Network grant to M.G, and funded in part by a Canadian Institutes of Health Research operating grant to IS (MOP-53277). I.S was the recipient of a Canadian Institute of Aging Investigator Award and J.D of an OGS award. Thanks to Dr. William Staines, and to QBM Cell Science for their technical assistance and use of the Multichannel systems Microelectrode Array system. In addition, thanks to Andrea $\mathrm{Yu}$ in the Griffith lab for her assistance with the cell counting.

\section{SUPPLEMENTARY MATERIAL}

Supplementary material is available on the publishers Web site along with the published article.

\section{REFERENCES}

[1] Laflamme MA, Chen KY, Naumova A V, et al. Cardiomyocytes derived from human embryonic stem cells in pro-survival factors enhance function of infarcted rat hearts. Nat Biotechnol 2007; 25: 1015-24

[2] van Laake LW, Passier R, Doevendans PA, Mummery CL. Human embryonic stem cell-derived cardiomyocytes and cardiac repair in rodents. Circ Res 2008; 102: 1008-10.

[3] Segers VF, Lee RT. Stem-cell therapy for cardiac disease. Nature 2008; 451: 937-42.

[4] Jawad H, Ali NN, Lyon AR, Chen QZ, Harding SE, Boccaccin AR. Myocardial tissue engineering: a review. J Tissue Eng Regen Med 2007; 1: 327-42.

[5] Gu Y, Yu J, Lum L G, Lee R J. Tissue engineering and stem cell therapy for myocardial repair. Front Biosci 2007; 12: 5157-65.

[6] Rabkin E, Schoen FJ. Cardiovascular tissue engineering. Cardiovasc Pathol 2002; 11: 305-17.

[7] Radisic M, Park H, Gerecht S, Cannizzaro C, Langer R, VunjakNovakovic G. Biomimetic approach to cardiac tissue engineering. Philos Trans R Soc Lond B Biol Sci 2007; 362: 1357-68.

[8] Chen SS, Fitzgerald W, Zimmerberg J, Kleinman HK, Margolis L. Cell-cell and cell-extracellular matrix interactions regulate embryonic stem cell differentiation. Stem Cells 2007; 25: 553-61.

[9] Christman KL, Lee RJ. Biomaterials for the treatment of myocardial infarction. J Am Coll Cardiol 2006; 48: 907-13.

[10] Rowlands AS, Hudson JE, Cooper-White JJ. From scrawny to brawny: the quest for neomusculogenesis; smart surfaces and scaffolds for muscle tissue engineering. Expert Rev Med Devices 2007; 4: 709-28.

[11] Zimmermann WH, Eschenhagen T. Embryonic stem cells for cardiac muscle engineering. Trends Cardiovasc Med 2007; 17: 134-40.

[12] McBurney MW, Jones-Villeneuve EM, Edwards MK, Anderson PJ. Control of muscle and neuronal differentiation in a cultured embryonal carcinoma cell line. Nature 1982; 299: 165-7.

[13] McBurney MW, Rogers BJ. Isolation of male embryonal carcinoma cells and their chromosome replication patterns. Dev Biol 1982; 89: 503-8.

[14] Paquin J, Danalache BA, Jankowski M, McCann SM, Gutkowska J. Oxytocin induces differentiation of P19 embryonic stem cells to cardiomyocytes. Proc Natl Acad Sci U S A 2002; 99: 9550-5. 
[15] Skerjanc IS, Petropoulos H, Ridgeway AG, Wilton S. Myocyte enhancer factor $2 \mathrm{C}$ and $\mathrm{Nkx} 2-5$ up-regulate each other's expression and initiate cardiomyogenesis in P19 cells. J Biol Chem 1998; 273: 34904-10.

[16] Grepin C, Dagnino L, Robitaille L, Haberstroh L, Antakly T, Nemer M. A hormone-encoding gene identifies a pathway for cardiac but not skeletal muscle gene transcription. Mol Cell Biol 1994; 14: 3115-29.

[17] Rudnicki MA, Jackowski G, Saggin L, McBurney MW. Actin and myosin expression during development of cardiac muscle from cultured embryonal carcinoma cells. Dev Biol 1990; 138: 348-58.

[18] Skerjanc IS. Cardiac and skeletal muscle development in P19 embryonal carcinoma cells. Trends Cardiovasc Med 1999; 9: 13943.

[19] Rossant J, McBurney MW. The developmental potential of a euploid male teratocarcinoma cell line after blastocyst injection. $\mathrm{J}$ Embryol Exp Morphol 1982; 70: 99-112.

[20] Janowski E, Cleemann L, Sasse P, Morad M. Diversity of Ca2+ signaling in developing cardiac cells. Ann NY Acad Sci 2006; 1080: $154-64$.

[21] van der Heyden MA, van Kempen MJ, Tsuji Y, Rook MB, Jongsma HJ, Opthof T. P19 embryonal carcinoma cells: a suitable model system for cardiac electrophysiological differentiation at the molecular and functional level. Cardiovasc Res 2003; 58: 410-22.

[22] Wobus AM, Kleppisch T, Maltsev V, Hescheler J. Cardiomyocytelike cells differentiated in vitro from embryonic carcinoma cells P19 are characterized by functional expression of adrenoceptors and $\mathrm{Ca}^{2+}$ channels. In Vitro Cell Dev Biol Anim 1994; 30A: 42534.

[23] Arreola J, Spires S, Begenisich $\mathrm{T}$. Na+ channels in cardiac and neuronal cells derived from a mouse embryonal carcinoma cell line. J Physiol 1993; 472: 289-303.

[24] Abilez O, Benharash P, Miyamoto E, Gale A, Xu C, Zarins CK. P19 progenitor cells progress to organized contracting myocytes after chemical and electrical stimulation: implications for vascular tissue engineering. J Endovasc Ther 2006; 13: 377-88.

[25] van der Heyden MA, Defize LH. Twenty one years of P19 cells: what an embryonal carcinoma cell line taught us about cardiomyocyte differentiation. Cardiovasc Res 2003; 58: 292-302.

[26] Grepin C, Nemer G, Nemer M. Enhanced cardiogenesis in embryonic stem cells overexpressing the GATA-4 transcription factor. Development 1997; 124: 2387-95.

[27] Kraehenbuehl TP, Zammaretti P, Van der Vlies AJ, et al. Threedimensional extracellular matrix-directed cardioprogenitor differentiation: syste-matic modulation of a synthetic cellresponsive PEG-hydrogel. Biomaterials 2008; 29: 2757-66.

[28] Nury D, Neri T, Puceat M. Human embryonic stem cells and cardiac cell fate. J Cell Physiol 2008.

[29] Gunning P, Ponte P, Blau H, Kedes L. alpha-skeletal and alphacardiac actin genes are coexpressed in adult human skeletal muscle and heart. Mol Cell Biol 1983; 3: 1985-95.

[30] Adra CN, Boer PH, McBurney MW. Cloning and expression of the mouse pgk-1 gene and the nucleotide sequence of its promoter. Gene 1987; 60: 65-74

[31] McBurney MW, Fournier S, Jardine K, Sutherland L. Intragenic regions of the murine Pgk-1 locus enhance integration of transfected DNAs into genomes of embryonal carcinoma cells. Somat Cell Mol Genet 1994; 20: 515-28.

[32] Norton PA, Coffin JM. Bacterial beta-galactosidase as a marker of Rous sarcoma virus gene expression and replication. Mol Cell Biol 1985; 5: 281-90.

[33] Ridgeway AG, Petropoulos H, Wilton S, Skerjanc IS. Wnt signaling regulates the function of $\mathrm{MyoD}$ and myogenin. J Biol Chem 2000; 275: 32398-405.

[34] Schmittgen TD. Real-time quantitative PCR. Methods 2001; 25: 383-5.

[35] Livak K J, Schmittgen T D. Analysis of relative gene expression data using real-time quantitative PCR and the 2(-Delta Delta $\mathrm{C}(\mathrm{T})$ ) Method. Methods 2001; 25: 402-8.

[36] Halbach M, Egert U, Hescheler J, Banach K. Estimation of action potential changes from field potential recordings in multicellular mouse cardiac myocyte cultures. Cell Physiol Biochem 2003; 13: 271-84.

[37] Reppel M, Pillekamp F, Lu ZJ, et al. Microelectrode arrays: a new tool to measure embryonic heart activity. J Electrocardiol 2004; 37 Suppl: $104-9$.
[38] Rudnicki MA, Ruben M, McBurney MW. Regulated expression of a transfected human cardiac actin gene during differentiation of multipotential murine embryonal carcinoma cells. Mol Cell Biol 1988; 8: 406-17.

[39] Anderson D, Self T, Mellor IR, Goh G, Hill SJ, Denning C. Transgenic enrichment of cardiomyocytes from human embryonic stem cells. Mol Ther 2007; 15: 2027-36.

[40] Klug MG, Soonpaa MH, Koh GY, Field LJ. Genetically selected cardiomyocytes from differentiating embronic stem cells form stable intracardiac grafts. J Clin Invest 1996; 98: 216-24.

[41] Schroeder M, Niebruegge S, Werner A, et al. Differentiation and lineage selection of mouse embryonic stem cells in a stirred bench scale bioreactor with automated process control. Biotechnol Bioeng 2005; 92: 920-33.

[42] Zandstra PW, Bauwens C, Yin T, et al. Scalable production of embryonic stem cell-derived cardiomyocytes. Tissue Eng 2003; 9: 767-78.

[43] Xu C, Police S, Rao N, Carpenter MK. Characterization and enrichment of cardiomyocytes derived from human embryonic stem cells. Circ Res 2002; 91: 501-8.

[44] Xu XQ, Zweigerdt R, Soo SY, et al. Highly enriched cardiomyocytes from human embryonic stem cells. Cytotherapy 2008; 10: 376-89.

[45] Kolossov E, Bostani T, Roell W, et al. Engraftment of engineered ES cell-derived cardiomyocytes but not BM cells restores contractile function to the infarcted myocardium. J Exp Med 2006; 203: 2315-27.

[46] Huber I, Itzhaki I, Caspi O, et al. Identification and selection of cardiomyocytes during human embryonic stem cell differentiation. Faseb J 2007.

[47] Fromstein JD, Zandstra PW, Alperin C, Rockwood D, Rabolt JF, Woodhouse K A. Seeding bioreactor-produced embryonic stem cell-derived cardiomyocytes on different porous, degradable, polyurethane scaffolds reveals the effect of scaffold architecture on cell morphology. Tissue Eng Part A 2008; 14: 369-78.

[48] Pari G, Jardine K, McBurney MW. Multiple CArG boxes in the human cardiac actin gene promoter required for expression in embryonic cardiac muscle cells developing in vitro from embryonal carcinoma cells. Mol Cell Biol 1991; 11: 4796-803.

[49] Skerjanc IS, McBurney MW. The E box is essential for activity of the cardiac actin promoter in skeletal but not in cardiac muscle. Dev Biol 1994; 163: 125-32.

[50] Parker KK, Ingber DE. Extracellular matrix, mechanotransduction and structural hierarchies in heart tissue engineering. Philos Trans R Soc Lond B Biol Sci 2007; 362: 1267-79.

[51] Masuda S, Shimizu T, Yamato M, Okano T. Cell sheet engineering for heart tissue repair. Adv Drug Deliv Rev 2008; 60: 277-85.

[52] Hu B H, Messersmith P B. Enzymatically cross-linked hydrogels and their adhesive strength to biosurfaces. Orthod Craniofac Res 2005; 8: 145-9.

[53] Lorand L, Conrad SM. Transglutaminases. Mol Cell Biochem 1984; 58: 9-35.

[54] Broderick EP, O'Halloran DM, Rochev YA, Griffin M, Collighan RJ, Pandit AS. Enzymatic stabilization of gelatin-based scaffolds. J Biomed Mater Res B Appl Biomater 2005; 72: 37-42.

[55] Ehrbar M, Rizzi SC, Schoenmakers RG, et al. Biomolecular hydrogels formed and degraded via site-specific enzymatic reactions. Biomacromolecules 2007; 8: 3000-7.

[56] McDermott MK, Chen T, Williams CM, Markley KM, Payne GF. Mechanical properties of biomimetic tissue adhesive based on the microbial transglutaminase-catalyzed crosslinking of gelatin. Biomacromolecules 2004; 5: 1270-9.

[57] Yung CW, Wu LQ, Tullman JA, Payne GF, Bentley WE, Barbari TA. Transglutaminase crosslinked gelatin as a tissue engineering scaffold. J Biomed Mater Res A 2007; 83: 1039-46.

[58] Orban JM, Wilson LB, Kofroth JA, El-Kurdi MS, Maul TM, Vorp DA. Crosslinking of collagen gels by transglutaminase. J Biomed Mater Res A 2004; 68: 756-62.

[59] Reppel M, Pillekamp F, Brockmeier K, et al. The electrocardiogram of human embryonic stem cell-derived cardiomyocytes. J Electrocardiol 2005; 38: 166-70.

[60] Satin J, Kehat I, Caspi O, et al. Mechanism of spontaneous excitability in human embryonic stem cell derived cardiomyocytes. J Physiol 2004; 559: 479-96.

[61] Wang X, Seed B. A PCR primer bank for quantitative gene expression analysis. Nucleic Acids Res 2003; 31: e154. 
[62] Wen J, Xia Q, Lu C, et al. Proteomic analysis of cardiomyocytes differentiation in mouse embryonic carcinoma P19CL6 cells. J Cell Biochem 2007; 102: 149-60.

[63] Rozen S, Skaletsky H. Primer3 on the WWW for general users and for biologist programmers. Methods Mol Biol 2000; 132: 365-86.
[64] Oustanina S, Hause G, Braun T. Pax7 directs postnatal renewal and propagation of myogenic satellite cells but not their specification. EMBO J 2004; 23: 3430-9.

(C) Dawson et al.; Licensee Bentham Open.

This is an open access article licensed under the terms of the Creative Commons Attribution Non-Commercial License (http://creativecommons.org/licenses/by$\mathrm{nc} / 3.0 /$ ), which permits unrestricted, non-commercial use, distribution and reproduction in any medium, provided the work is properly cited. 